 \\ Специфика функционирования лексемы «жар-птица» в русском языке
}

\author{
Зубкова Е. Н.
}

\begin{abstract}
Аннотация. Цель исследования - выявить бытование номинации «жар-птица» в контекстах, относящихся ко второй половине XIX - началу XXI в., специфику развития прямого значения данной номинации за счет переносных употреблений. Научная новизна работы заключается в изучении семантики лексемы «жар-птица»с точки зрения ее функционирования в качестве переносных названий реальных лиц или объектов, что прежде не являлось предметом исследования литературы. В результате впервые было выявлено, что в русской лингвокультуре семантическая структура лексемы «жар-птица» в переносных употреблениях постепенно утрачивает компоненты, связанные с мифологическим антропоцентризмом, и, в частности, компонент ‘одушевленность' .
\end{abstract}

\section{The Functioning of the Lexeme “Жар-Птица” (Firebird) in the Russian Language}

\section{Zubkova E. N.}

\begin{abstract}
The research objectives are as follows: to examine the functioning of “жар-птица" (firebird) lexeme in the discourses of the second half of the XIX - the beginning of the XXI century, to analyze the actualization of its direct meaning in a figurative context. Scientific originality of the study lies in the fact that for the first time in domestic linguistics the author analyzes the semantics of “жар-птица” (firebird) lexeme taking into account the specificity of its figurative usage. The conducted research allows concluding that in the modern Russian language the lexeme “жар-птица” (firebird) gradually loses semantic meanings associated with mythological anthropocentrism, in particular, the meaning "animateness".
\end{abstract}

\section{Введение}

В статье проанализированы особенности развития семантики лексемы жар-птица со значением '(фантастическая) мифологическая птица' в русской языковой картине мира. Актуальность данной статьи определяется важностью разработки лингвокультурологической проблематики русского языка на материале номинаций, сохранивших в своей семантике мифологические элементы языкового сознания, а также значительным интересом современного лингвистического сообщества к наивной картине мира.

В статье анализируется модификация семантики номинации жар-птица, которая относится к лексикосемантической группе «Фантастические птицы». Под фантастическими птицами, с опорой на материалы «Словаря современного русского литературного языка (Большого академического словаря)» [10, стб. 1250-1251] и этнолингвистического словаря «Славянские древности» под редакцией Н. И. Толстого [9, с. 345], мы будем понимать группу животных персонажей, являющихся плодом фантазии народной культуры и не существующих в действительности, которые отличаются способностью летать и неспособностью ползать. Модификация семантики номинации жар-птица связана, таким образом, с развитием метафорической и метонимической контекстной полисемии. Поставленная цель обеспечивается решением следующих задач: во-первых, рассмотреть способы расширения прямого значения номинативных слов; во-вторых, выявить основные направления развития метафорической контекстной полисемии лексемы жар-птица; в-третьих, выявить основные направления развития метонимической контекстной полисемии этой же номинации.

Материалы исследования были получены в ходе работы с дефинициями, извлеченными из русских толковых и этнолингвистических словарей, и данными Основного подкорпуса Национального корпуса русского языка (далее - НКРЯ, цитирование опирается на материалы НКРЯ).

Ведущими в работе являются следующие методы исследования: общенаучные теоретические методы (метод наблюдения, описания, обобщения), метод анализа словарных дефиниций и метод компонентного анализа значения слова при работе с лексикографическими источниками, корпусный метод для отбора материала исследования, метод контекстного анализа смыслов лексемы при работе с контекстами бытования лексемы. 
На основе контекстов бытования лексемы жар-птица, полученных с помощью метода сплошной выборки примеров в Национальном корпусе русского языка, автором установлено, что в русском языке для исследуемой номинации характерно развитие метафорической и метонимической контекстной узуальной полисемии, связанной с гендерной и этнической принадлежностью птицы, ее сущностной и функциональной характеристикой, описанием внешности и способностей.

Теоретической базой исследования послужили работы отечественных (Ю. Д. Апресян [1], И. М. Кобозева [2], Э. В. Кузнецова [5], Л. А. Новиков [8]) и зарубежных авторов (Дж. Лакофф и М. Джонсон [6]), в которых рассматриваются вопросы развития семантики лексических единиц.

Практическая значимость исследования заключается в том, что полученные результаты могут использоваться в учебном процессе при подготовке к лекционным, практическим и семинарским занятиям по лингвокультурологии и лексической семантике на лингвистических и филологических факультетах высших учебных заведений. Кроме того, результаты исследования могут использоваться в лексикографической практике.

\section{Основная часть}

Изменение семантики слова может происходить за счет развития у него многозначности. Различают метафорическую и метонимическую полисемию в зависимости от характера языковой мотивированности значений многозначного слова [11, с. 199-201].

Метафора - «слово или оборот речи, употребленные в переносном значении для определения предмета или явления на основе какой-либо аналогии, сходства» [12, с. 458]. Метафорическая связь значений представляет собой их взаимную языковую мотивированность в силу сходства формы, внешнего вида, производимого впечатления, местоположения, структуры действия, оценки или выполняемой функции [8, с. 198-200].

Метонимия - слово или выражение, «переносное значение которого основано на внешней или внутренней связи (смежности) двух предметов или явлений» [3, с. 209]. Метонимическая связь значений базируется на смежности действия и результата (места, инструмента, субъекта действия), свойства и имеющего это свойство предмета, вместилища и вместимого, части и целого, предмета и изделия (материала, продукта), профессии (звания, чина) и имеющего их человека и т.д. [8, с. 195-197].

Подчеркнем, что оба типа полисемии предполагают появление у слова переносного значения либо употребления (в нашей работе изучаются переносные узуальные употребления). Вторичные по своей природе, они всегда опираются на основное прямое значение лексемы. «Денотат основного значения присутствует в переносном в качестве 'внутренней формы', как указание на предмет, на основе сходства с которым названо явление, составляющее собственный денотат переносного значения» [5, с. 111]. Со временем при частном употреблении переносное значение может утратить свою образность и стать одним из неосновных прямых значений лексемы.

В ходе исследования было обнаружено, что в русской языковой картине мира семантика лексемы жарптица развивается, в том числе, за счет появления у номинации переносных контекстных употреблений. Рассмотрим их подробнее.

«Свойство механизмов метафоры сопоставлять, а затем и синтезировать сущности, соотносимые с разными логическими порядками, обусловливает ее продуктивность как средства создания новых наименований, особенно в сфере обозначения объектов невидимого мира. И в этом важную роль играет наиболее характерный для метафоры параметр - ее антропометричность» [4, с. 182]. Анализ словарных дефиниций лексемы жарптица позволил обнаружить антропометричность ее значения, которая выражается через присутствие в структуре семантики двух систем из «сферы человека», выделенных Ю. Д. Апресяном, - физического восприятия (птица воспринимается зрением и слухом) и физического действия и деятельности (птица выступает субъектом и объектом действия) [1, с. 42-43]. Репрезентация данного параметра лежит в основе когнитивных метафор, образованных по модели НЕЧТО (область-цель/мишень) ЕСТЬ НЕКТО (область-источник) и частично НЕЧТО (область-цель/мишень) ЕСТЬ НЕЧТО-1 (область-источник). Подобная метафора «неформально определяется как способ думать об одной области через призму другой, перенося из области-источника в область-мишень те когнитивные структуры, в терминах которых структурировался опыт, относящийся к области-источнику» [2, с. 171]. Область-цель/мишень представляет собой явление, которое носитель языка хочет назвать, область-источник это та сфера, из которой говорящий черпает хорошо известные ему сведения.

В «Словаре русской ментальности» В. В. Колесова отмечается (без иллюстративных примеров), что на базе значения '(мифологическая) фантастическая птица' лексема жар-птица может репрезентировать метафорические употребления, основанные на модели когнитивной метафоры НЕЧТО ЕСТЬ НЕЧТО-1 (5 вариантов), ‘счастье’, ‘удача', ‘неуловимая судьба', ‘недостижимая мечта’ и ‘молодость’ [4, с. 254]. В данных переносных употреблениях метафорическая связь происходит на основе сходства функции (первые четыре употребления) или способностей (последнее употребление). В полученном нами прозаическом материале из НКРя подтверждаются все метафорические контекстуальные значения, кроме значения 'молодость'.

Среди прозаических документов, представленных в НКРЯ, мы нашли 17 вариантов контекстуального метафорического переноса прямого значения лексемы жар-птица '(мифологическая) фантастическая птица' по указанным выше моделям (5 и 12 вариантов соответственно) [7]. В переносных значениях, основанных на модели НЕЧТО ЕСТЬ НЕКТО, метафорическая связь осуществляется:

- метафорическая связь с областью-источником (жар-птища) по сходству внешности или производимого впечатления: ‘реальная птица, внешне похожая на жар-птицу’ (область-цель): «Речная жар-птица. 
Всякий раз, рассматривая фотографии этой птицы, мне кажется, что предо мной какое-то сказочное райское создание, рождённое не иначе как в жарких странах. Голова и спина золотисто-коричневые, через глаза проходит чёрная полоса, горло жёлтое, брюшко синее, почти бирюзовое, крылья буровато-сизые, хвост зелёный» (Василий Вишневский. Речная жар-птица // Наука и жизнь. 2008); 'светящееся животное’ (область-цель): «Объяснение простое: на перьях поселяются светящиеся микроорганизмы. Вот вам и “жар-птица” из сказки!» (В. А. Мезенцев. Чудеса: популярная энциклопедия. Том 1. Книга 2 (1991)); ‘фазан’ (область-цель): «А вспыхивающее под ярким солнцем разноцветное пламя наших жар-птиц - фазанов!» (В. В. Бианки. Рассказы (1950-1958)// Наука и жизнь. 2007); “красивая женщина, имеющая нечто золотое или серебряное во внешнем облике’ (область-цель): «...она направляется к отцу. Все на нее дивятся: “Жар-Птица, прямо”, - такая она красавица! Так и блестит на солнце от золотистой кожи, от серебряного седла, от глаз» (И. С. Шмелев. Лето Господне (1927-1944)); 'человек, выделяющийся по каким-либо качествам из ряда других людей’ (областьцель): «Слушали Каина куры на насесте, слушала Надежда, не понимая, чего ему надо, и замирая, и прижимаясь, и чудилась ей рядом какая-то диковинная жар-птица, а не случайный в их деревне проезжий...» (Б. Б. Вахтин. Три повести с тремя эпилогами / Ванька Каин (1959-1964)).

В переносных употреблениях, основанных на модели НЕЧТО ЕСТЬ НЕЧТО-1, метафорическая связь осуществляется:

- метафорическая связь с областью-источником (жар-птица) по сходству внешних признаков: ‘нечто, напоминающее внешне жар-птицу’ (область-цель): «Заметив, что пацан подглядывает, настигла, перемахнув стрелой перила - стремительно голые смуглые ноги в раскрытом оперении юбки мелькнули жар-птицей над опрокинутым взглядом» (Александр Иличевский. Кефаль (2005)); ‘головной убор с перьями' (областьцель): «Платье на ней, как лен цветет... а на головке - жар-птицы хвост...» (А. Н. Толстой. Петр Первый. Книга третья (1944)); ‘нечто сверкающее’ (область-цель): «Оторвав глаз от камня, увидел золотистого “королевского” ерша. На мрачном пасмурном фоне он казался чудесной жар-птищей» (П. Курилов. У Кекур пять пальцев // Спортсмен-подводник. 1966);

- метафорическая связь с областью-источником (жар-птища) по сходству производимого впечатления: 'нечто несбыточное' (область-цель): «Почему они думают, что, если младенцу, например, прочитать “Конька-горбунка”, он непременно отвратится от всякой механики и до старости лет будет мечтать о жарптицах?» (К. И. Чуковский. От двух до пяти (1933-1965)); 'нечто невиданное, необычное’ (область-цель): «Пусть уж о прелестях современности пишет Брюсов, а я поищу Жар-Птицу...» (В. Ф. Ходасевич. Есенин (1926)); 'нечто горящее (костер, фейерверк, искры, пламя)' (область-цель): «Гуд превращался в гул, а там и в могучий рев, оранжево-темное пятно появлялось посредине страницы, оно вдруг взрывалось пламенем, и огромный горящий лист с фырчащим шумом освобожденного феникса улетал в трубу к звездам. Приходилось платить несколько шиллингов штрафа, если властям доносили об этой жар-птице» (В. В. Набоков. Другие берега [переработанный автоперевод с английского] (1954)); 'нечто, напоминающее солнце' (область-цель): «Что это? Твоя Жар-птица, Макс, - солнце!» (М. И. Цветаева. Живое о живом (Волошин) (1932)); 'нечто, подобное вдохновению’ (область-цель): «Великий Гёте кружил по комнате как орел, и стоило мелькнуть фразе, мысли, образу - он бросался к первому, рядом стоящему столу или конторке и не давал улететь сверкнувшей жарптице или даже разноперому мелкому колибри. Хватал на лету и тут же запихивал в строчки, зарешечивал переплетом букв» (Виктор Розов. Удивление перед жизнью (1960-2000)); 'нечто редкое' (область-цель): «Вот мол, до чего вы, скоты, дожили, что честный-то человек у вас словно жар-птица!» (М. Е. Салтыков-Щедрин. Губернские очерки (1856-1857));

- метафорическая связь с областью-источником (жар-птица) по функциональному сходству: 'нечто, являющееся труднодостижимым (цели, факты, мечты, призвание)’ (область-цель): «За какой жарптицей носило ее по морям? Заработок - ну что ж, это конечно тоже нужно, но теперь - кооперативная квартира, ковры, японская аппаратура - все есть...» (Олег Глушкин. Возвращение (1990-1999)); 'нечто, являющееся главной частью чего-то, сутью (бессмертия, долголетия, мысли, удачи)’ (область-цель): «Определили, например, генетики, что ген АроЕ у человека действительно влияет на продолжительность жизни, как тут же им померещилось, что еще один шаг - и они поймают за хвост жар-птищу бессмертия» (Зиновий Юрьев. Смертельное бессмертие // Наука и жизнь. 2007); 'то, что достается (успех, слава, судьба, удача)' (область-цель): «Нам самим свою Жар-птицу ловить, коли есть хоть какая к тому способность. Кто за хвост ее ухватит, кто за горло возьмет, кто за когти уцепится, крови своей не щадя, кто хитрую ловушку для нее смастерит или сладкозвучным пением своим заворожит ее» (Борис Васильев. Картежник и бретер, игрок и дуэлянт (1998)); «К тому же в ближайшие несколько дней и в любви можно поймать жар-птицу за хвост» (Павел Максимов. Астрологический прогноз Павла Максимова // Автопилот. 2002.09.15).

Данные переносные употребления лексемы жар-птица расширяют денотативный объем содержания изучаемой номинации и базируются на следующих семах прямого значения: 'сущностная характеристика' (‘фантастическая’, ‘сказочная’, ‘необычная’, ‘диковинная’), ‘этническая характеристика’ ('русская’), ‘характеристика внешности’ ('сияющая’, ‘золотая и серебряная’, ‘синяя’, ‘с изумрудным сиянием’, ‘пестрая’, ‘прекрасная’), 'характеристика как двигателя сюжета’ ('за которой посылают, которая добывается, которую ищут)', ‘приносящая благо’, 'награда герою’, ‘характеристика способностей’ (‘быстрая’).

Механизм метонимии, согласно Дж. Лакоффу и М. Джонсону, строится на том, что одна сущность используется для ссылки на другую, связанную с ней, что позволяет более точно сконцентрироваться на определенной стороне обозначаемого. При этом основания метонимических концептов является более очевидным, потому что содержат явные указания на физические или причинные ассоциации [6, с. 62-63]. 
Метонимические переносные контекстные употребления лексемы жар-птица встречаются реже. Они актуализируют, прежде всего, внешний облик птицы в виде ее изображения или художественного представления через модели НЕЧТО ЕСТЬ НЕКТО и НЕЧТО ЕСТЬ НЕЧТО-1, которые реализуются в таких вариантах: художественное произведение - его исполнительница, скульптура - ее номинация, словесное описание произведение, в котором оно представлено.

Среди прозаических документов, представленных в НКРЯ, мы нашли 3 варианта метонимического переноса прямого значения лексемы жар-птица '(мифологическая) фантастическая птица' по указанным выше моделям [7]. В переносных употреблениях, основанных на модели НЕЧТО ЕСТЬ НЕКТО, метонимическая связь осуществляется:

- метонимическая связь с областью-источником по смежности художественного образа жар-nтuщы и его исполнителя: 'исполнительница художественного образа' (область-цель): «Фокин использовал высокий прыжок Карсавиной - Жар-птица разрезала сцену как молния... Жар-птица Тамары Карсавиной стала одним из символов времени» (Елена Гиль. «Она летит легко, проворно, так радостно парит она» // Вестник США. 2003.06.25).

В переносных значениях, основанных на модели НЕЧТО ЕСТЬ НЕЧТО-1, метонимическая связь осуществляется:

- метонимическая связь с областью-источником по смежности художественного изображения жар-nтuщы и его исполнительницы: 'название скульптуры в качестве приза певцам' (область-цель): «Мы решили вручать всем приехавшим на биеннале певцам памятный приз “Жар-птица”...» (И. К. Архипова. Музыка жизни (1996));

- метонимическая связь с областью-источником по смежности художественного изображения жар-nтuцы и названия произведения, на котором оно представлено: 'название этого предмета искусства' (область-цель): «"Инфанта" его же кисти стоит уже дороже. Работы Данилы Меньшикова "Шахерезада" и “Жар-птица" (20-25 mыс.)» (Сергей Самойленко. Картины к Рождеству // Континент Сибирь (Новосибирск). 2004.12.17).

Подчеркнем, что метонимические употребления лексемы жар-птица основываются на семантических компонентах прямого значения 'гендерная характеристика' ('феминность'), 'общая характеристика внешности’ и связаны с материальным художественным изображением птицы, называемой изучаемым словом.

\section{Заключение}

Проанализировав представленные в НКРЯ контексты бытования лексемы жар-птuца, мы пришли к следующим выводам: развитие ее семантики происходило благодаря появлению метафорического и метонимического осмысления содержания слова, которое выразилось в узуальных контекстных употреблениях лексемы жар-птица.

Метафорическая контекстная полисемия лексемы жар-птица основывается на сходстве внешности, производимого впечатления, функции и соотнесенности структуры оценки; метонимическая опирается на семы прямого значения, входящие в группу 'характеристика внешности' и 'гендерная характеристика'. В контекстной метафоре областью-целью выступают вид животного, человек, обладающие определенными качествами, абстрактное понятие, конкретный предмет, а областью-источником - совокупность свойств жарптицы. В контекстных метонимиях областью целью выступают название исполнительницы художественного образа, скульптуры, картины, а областью источником - художественное изображение или образ жар-птицы (в том числе воплощаемый кем-то).

Использование номинации фантастической птицы для наименования людей указывает на актуализацию ее изначальной мифологической антропоморфности, а употребление лексемы жар-птица для обозначения абстрактных сущностей, предметов позволяет сделать вывод о постепенном утрачивании ею мифологических семантических компонентов.

Закрепившееся в русском языке как основное прямое значение слова жар-птица '(мифологическая) фантастическая птица' позволяет носителю языка легко идентифицировать основания метафорической и метонимической связи и при необходимости создавать по аналогичным моделям новые переносные употребления слова.

Перспективы дальнейшего исследования проблемы мы видим в более детальном изучении специфики функционирования прямого значения номинации жар-птица в поэзии и художественной литературе, а также в выявлении общих закономерностей развития переносных контекстных употреблений номинаций, входящих в лексико-семантическую группу «Фантастические птицы».

\section{Финансирование | Funding}

RU Публикация подготовлена в рамках поддержанного РФФИ научного проекта № 20-31-70001, проект «Лексико-семантическая группа “фантастические птицы” как фрагмент русской языковой картины мира: история и современное состояние». 


\section{Источники | References}

1. Апресян Ю. Д. Образ человека по данным языка: попытка системного описания // Вопросы языкознания. 1995. № 1. С. 37-67.

2. Кобозева И. М. Лингвистическая семантика: учебник. М.: Эдиториал УРСС, 2000. 352 с.

3. Кожина М. Н., Дускаева Л. Р., Салимовский В. А. Стилистика русского языка: учебник. Изд-е 4-е, стереотип. М.: Флинта; Наука, 2008. 464 с.

4. Колесов В. В., Колесова Д. В., Харитонов А. А. Словарь русской ментальности: в 2-х т. СПб.: Златоуст, 2014. T. 1. A - O. 592 c.

5. Кузнецова Э. В. Лексикология русского языка: учеб. пособие для филол. фак. ун-тов. Изд-е 2-е, испр. и доп. М.: Высш. шк., 1989. 217 с.

6. Лакофф Дж., Джонсон М. Метафоры, которыми мы живем / пер. с англ.; под ред. и с предисл. А. Н. Баранова. М.: Едиториал УРСС, 2004. 256 с.

7. Национальный корпус русского языка (НКРЯ) [Электронный ресурс]. URL: http://www.ruscorpora.ru (дата обращения: 30.05.2021).

8. Новиков Л. А. Семантика русского языка: учеб. пособие. М.: Высш. школа, 1982. 272 с.

9. Славянские древности: этнолингвистический словарь: в 5-ти т. / под общ. ред. Н. И. Толстого. М.: Международные отношения, 2009. Т. 4. 656 с.

10. Словарь современного русского литературного языка: в 16-ти т. / глав. ред. чл.-кор. АН СССР В. И. Чернышев; Акад. наук СССР; Ин-т рус. яз. М. - Л.: Изд. и 1-я тип. Изд-ва Акад. наук СССР в Л., 1964. Т. 16. У-Ф. 1610 стб.

11. Современный русский язык: учеб. для филол. спец. ун-тов / под ред. В. А. Белошапковой. Изд-е 2-е, испр. и доп. М.: Высш. шк., 1989. 800 с.

12. Стилистический энциклопедический словарь русского языка / под ред. М. Н. Кожиной; чл. редколл. Е. А. Баженова, М. П. Котюрова, А. П. Сковородников. Изд-е 2-е, испр. и доп. М.: Флинта; Наука, 2006. 696 с.

\section{Информация об авторах | Author information}

RU Зубкова Елена Николаевна

${ }^{1}$ Северо-Кавказский федеральный университет, г. Ставрополь

EN Zubkova Elena Nikolaevna ${ }^{1}$

${ }^{1}$ North-Caucasus Federal University, Stavropol

${ }^{1}$ helen_zubkova@mail.ru

\section{Информация о статье | About this article}

Дата поступления рукописи (received): 01.07.2021; опубликовано (published): 30.09.2021.

Ключевые слова (keywords): семантика; переносное употребление; контекстная метафора; контекстная метонимия; лексема жар-птица; semantics; figurative usage; contextual metaphor; contextual metonymy; lexeme “жар-птица” (firebird). 